\title{
Vestiges of Ossified Spheno-occipital Suture in an Elderly Patient With Down Syndrome and Lateral Skull Base Fracture
}

\author{
REINHARD E. FRIEDRICH ${ }^{1}$, FELIX K. KOHLRUSCH ${ }^{1}$ and ULRICH GRZYSKA ${ }^{2}$ \\ ${ }^{1}$ Department of Oral and Craniomaxillofacial Surgery, Eppendorf University Hospital, \\ University of Hamburg, Hamburg, Germany; \\ ${ }^{2}$ Department of Neuroradiology, Eppendorf University Hospital, \\ University of Hamburg, Hamburg, Germany
}

\begin{abstract}
Background/Aim: Down syndrome (DS) patients often show characteristic changes in the skull, e.g. short cranial base. The synchondroses of the skull base have a significant influence on the shape of the skull. The sphenooccipital synchondrosis (SOS) is the last of the basal synchondroses to ossify. This report is about residual ossification of SOS in an elderly patient with DS. Case Report: The 65-year-old DS patient was polytraumatized by a fall. In the course of treatment, a purulent otitis externa on the right side was diagnosed, which had developed as a result of the fracture of the fossa glenoidalis. Computed tomograms of the skull base showed the fracture of the mandibular condyle, glenoid fossa and vestiges of SOS. Conclusion: The coincidental finding of vestiges of SOS in an elderly patient with DS raises the question of whether cross-sectional skull base images can show differences in the ossification of SOS between DS patients and a normal population.
\end{abstract}

Sphenoocipital synchondrosis (SOS) forms the cartilaginous connection between the sphenoid and the basi-occipital bone (1-3). This synchondrosis is considered an important growth zone of the skull base and usually ossifies towards the end of the second decade of life (4-11). Residues of SOS can be demonstrated on radiological sectional images of complete ossified bones in young adults, but also in later phases of life, even in old age (12). It is a radiologically known variety

This article is freely accessible online.

Correspondence to: Reinhard E. Friedrich, MD, DMD, Ph.D., Oral and Craniomaxillofacial Surgery, Eppendorf University Hospital, University of Hamburg, Martinist. 52, 20246 Hamburg, Germany. Tel: +49 40741053259, e-mail: rfriedrich@uke.de

Key Words: Spheno-occipital synchondrosis, Down syndrome, skull base, fracture, ossification. whose causes are unknown and is usually of no pathological significance (12). In cases showing incomplete closure or inhomogenous vestiges of SOS, the differential diagnosis of a radiological variant of suture ossification and a skull base fracture is of primary diagnostic interest $(13,14)$. Early ossification of SOS has been demonstrated in various craniofacial syndromes with shortened skull base as a cardinal finding (15). In cases with craniofacial syndromes, in addition to the shortening of the skull base, there is also frequently a change in the skull base angle as determined by the lines Nasion - Sella and Sella - Basion (NSBa angle) (1619). Patients with craniofacial syndromes are often characterized by midface hypoplasia, the extent of which correlates with the time of early SOS ossification (15).

Several studies have examined the skull base of Down syndrome patients (20-27). Down syndrome patients have a shortened anterior and posterior skull base (25). It is assumed that, as with some other craniofacial dysmorphisms, SOS ossifies early in Down syndrome patients and this is an important factor in sagittal shortening of the skull base (24). Persistent vestiges of the SOS may announce a delayed or incomplete ossification of the SOS and at least in individual radiological findings, question the hypothesis of a very early ossification of this synchondrosis in Down syndrome. The following report is about the detection of SOS vestiges in an elderly Down syndrome patient.

\section{Case Report}

The demented 65-year old male patient with established diagnosis of trisomy 21 was living in a nursing home and, according to the caregiver, had fallen and was seriously injured about 10 days ago. He had suffered a femur and radius fracture that had already been treated. A few days after these surgical procedures, the patient developed a purulent secretion of the right ear canal that required medical examinations. Promethazine was taken as permanent medication. 

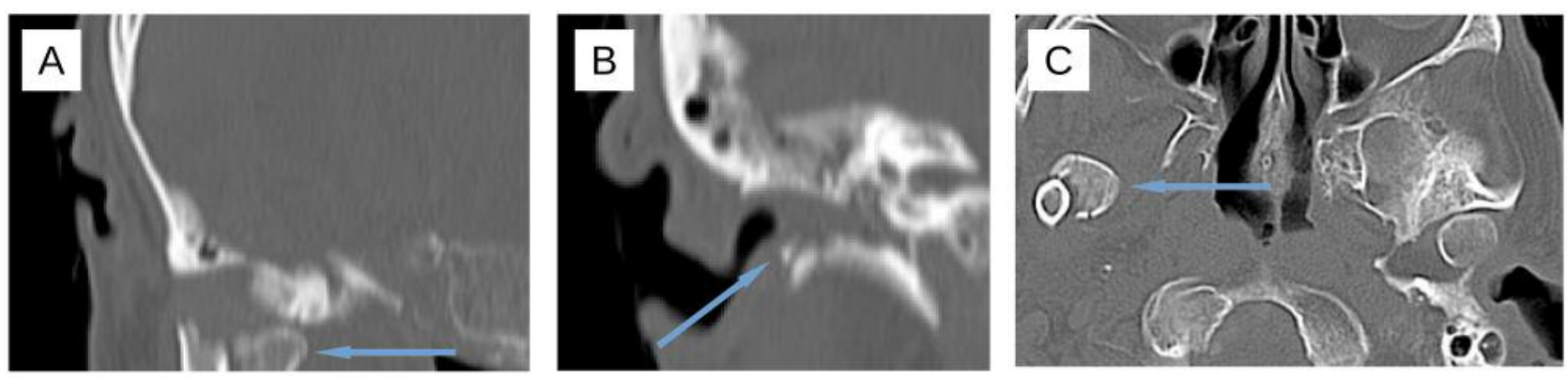

Figure 1. Computed tomograms of skull base of a 65-year-old male with Down syndrome show: A) on the coronal view the medially dislocated fractured right articular condyle (arrow), B) on detail of coronal view the fractured glenoid fossa (arrow), and C) on the axial view the articular condyle medial to the condylar neck.

During the initial examination, the edentulous patient showed pressure pain over the right preauricular region, intact oral mucosa and no pathological mobility in the area of the mandibular body. Pressure on the chin caused pain in the right temporo-mandibular joint (TMJ) area. The otological examination confirmed the torn ear canal as the cause of purulent secretion. A cranial computed tomogram (CT) was made to confirm supected fracture of glenoid fossa and to examine other potential traumatic damage to the skull and brain. CT showed the dislocated fracture of the right articular condyle and small bony fragments limited to the glenoid fossa, obliteration of right mastoid cells with radiopaque structures isointense to fluid, focal ossification in basal regions of the brain and substantial expansion of the ventricles, but no further trauma consequences to the skull and brain (Figure 1). The successful treatment of external otitis and skeletal trauma was conservative with antibiotics and regular wound cleaning.

The CT of the skull also showed the entire skull base. In the area of the craniocervical junction, posterior to the dorsum sellae, a bilamellar hyperintense structure running almost perpendicular to the clivus surface traversed completely the bone from one side to the other. These white lines were as dense as the adjacent cortical bone. The two visible hyperdense sclerosed lines were running parallel to each other and delimited from both sides by a small line with a radiopacity isointense to the cancellous bone located at both sides of these structures. This arrangement of lines was assessed as SOS vestiges, which could be identified on sagittal and axial planes (Figure 2). The patient had not developed a frontal sinus. The sphenoid sinus was only developed presellarly. Nasion-Sella-Basion (NSBa) angle was $134^{\circ}$. As a further finding, both carotid syphons were arteriosclerotic.

\section{Discussion}

This report describes the late diagnosis of a lateral skull base fracture in a patient with Down syndrome and the random finding of SOS vestiges on computed tomography (CT) of the skull base. CT diagnosis confirmed some characteristics of the skull that are typical for Down syndrome patients, e.g. lack of the frontal sinus [in approximately $85 \%$ of cases (21)], and calcification of the basal ganglia (22) (Figure 2). Most radiological studies on skull morphology in Down syndrome are based on plain radiographs $(20,21,23,24)$. What is interesting in this case is the patient's well-known underlying genetic disorder in connection with the osseous variant of the skull base. So far, there is no report of a trisomy 21 patient over 60 years old with vestiges of SOS. Hypoplasia of the sphenoid sinus and the incomplete absorption of the synchondrosis were frequently coincidental findings in healthy individuals (1). It seems reasonable to assume a connection between the known trisomy 21 of the patient, sphenoid sinus hypoplasia, and vestige of SOS.

SOS and skull base development. The interest in the shape and transformation of the sphenooccipital synchondrosis is mainly due to the importance of this suture in the development of the skull base $(4,15)$. An early closure of the skull base sutures is associated with a shortened phase of the extensibility of the skull base in the anterior-posterior direction, but also for the adjustment of the skull base in the vertical dimension (15). Okamoto et al. (1) described the connection between vestige of SOS in 48 out of 51 cases with limited sphenoid bone sinus on high-resolution CT. In these cases, a white line was visible dorsal to the dorsal border of the sphenoid bone aeration. SOS vestiges were not identified in $55.7 \%$ of individuals, all with sphenoid sinus extending into the occipital bone. However, the authors do not state the age range in which a connection between low sphenoid bone aeration and vestige of the SOS was observed (1).

Classification of SOS ossification. Different stages are distinguished in the gradual fusion of SOS. In the classification of Bassed et al. (28) the final stage of SOS fusion is reached when there is complete ossification between the two bones. The classification distinguishes four 

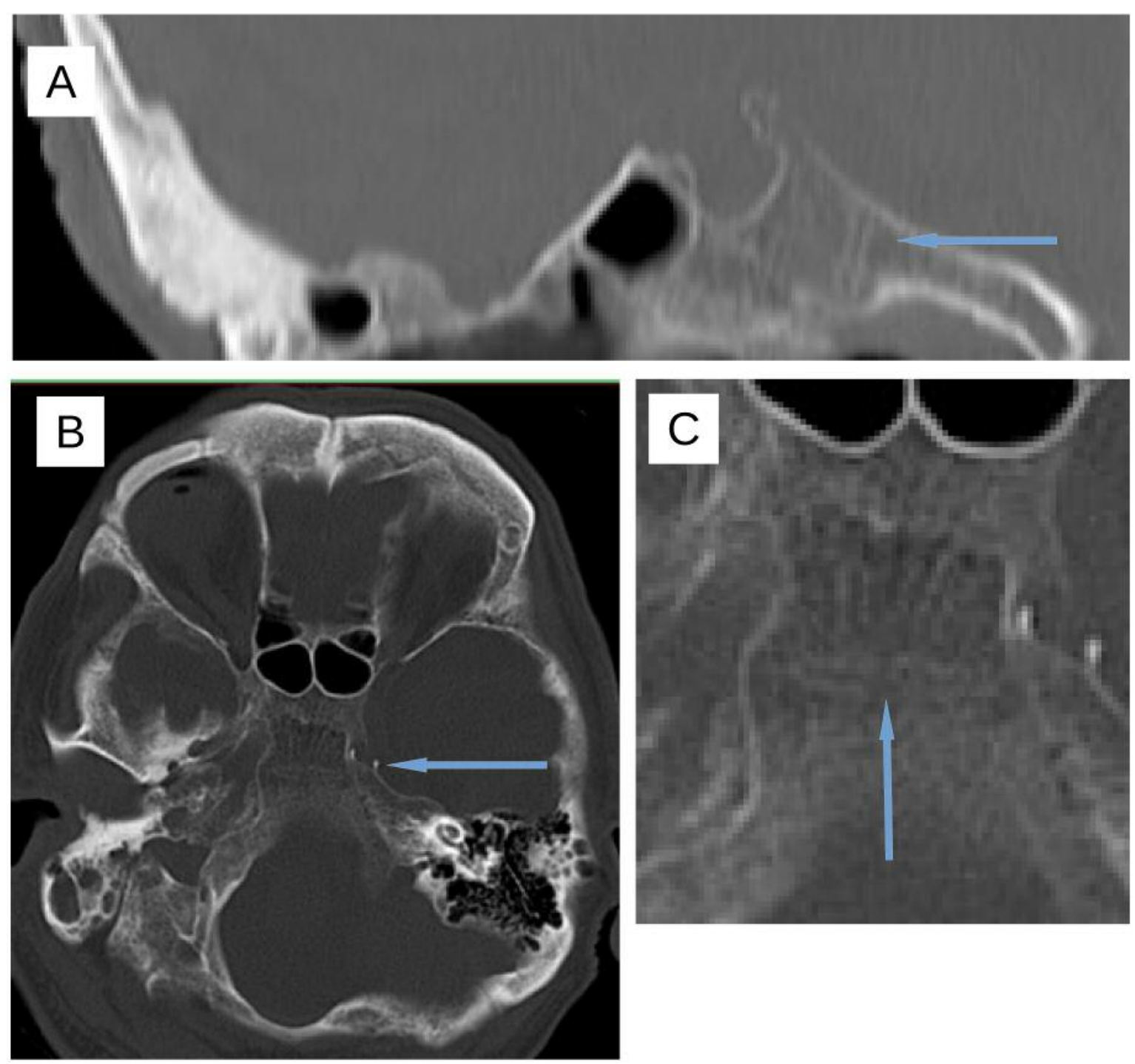

Figure 2. A) Sagittal section of cranial computed tomogram of a 65-year-old male with Down syndrome shows aplasia of frontal sinus (shown anterior skull base pneumatization is anterior-superior part of ethmoid), sphenoid bone pneumatization restricted to presellar region, and vestiges of sphenooccipital suture (arrow). B) Axial section of CT shows radiopaque right mastoid, missing frontal sinus and vestiges of sphenooccipital suture (arrow). C) Detail of Figure $2 B$ shows vestige of the suture in detail.

stages, and was primarily developed for the forensic age diagnosis of children and adolescents. Residuals of the SOS can occur, which are called 'scars'. Bassad et al. (28) make no distinction between an ossification stage with vestiges ('scars') of SOS and a complete ossification of the suture without remnants of the former growth plate.

In contrast, in their classification of SOS closure, Madeline and Elster (29) differentiate a stage of ossification with vestiges of SOS (stage 4) from the terminal stage of ossification (stage 5) (Figure 3). The terminal stage of ossification is defined to show complete fusion of bones with no vestige of former synchondrosis (29). This second classification is more suitable for capturing persistent structural disorders of the (late) ossification (29). According to these classifications, the final stage of ossification was reached in the presented patient only in the classification addressing the suitability of SOS ossification for age estimating purposes (28). Residual levels of incomplete ossification of SOS are a skeletal normal variant observed relatively frequently. The vestiges appear as fading sclerotic regions or translucences in the area of the former SOS, but also as smaller defects that cause cleft-like indentations of the bone, plus ossified bodies within a space filled with cartilage that can still ossify (12). The hard tissue 

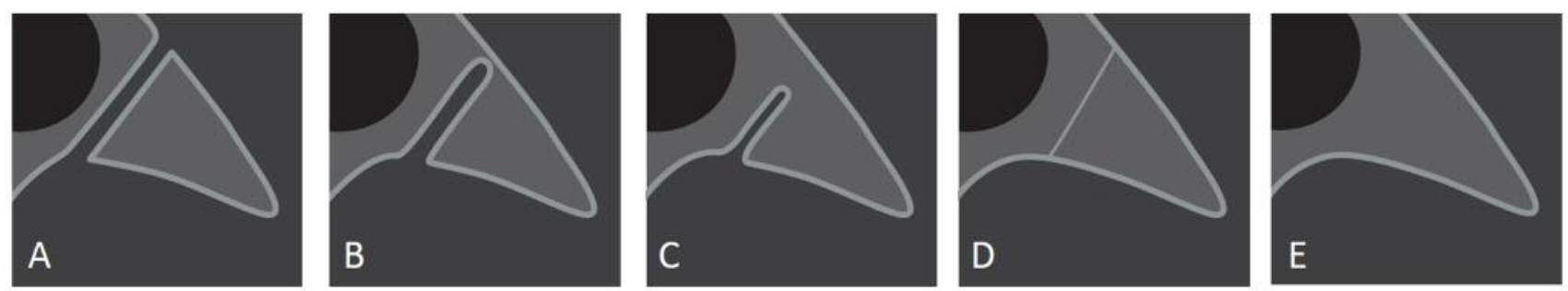

Figure 3. A greatly simplified diagram of the stages of sphenooccipital suture ossification in a lateral view (anterior is to the left). The ossification increases from A to E. In A), basi-occiput and sphenoid are separated when synchondrosis is completely intact. A cortical layer limits both bones to the gap. In B) begins the ossification, which starts from the endocranial side. C) describes an intermediate stage of ossification with synchondrosis open to the ectocranial side. In D) the synchondrosis is closed. Remains of synchondrosis can be detected as line(s) equivalent to corticalis in lateral X-ray images. In E) both bones are completely fused together.

transformation disorders can occasionally occur even in old age and are harmless variants of bone formation. The biological significance of these vestiges is unknown. However, isolated cases can arise in which this ossification disorder was associated with pathological disorders (30).

Development and fusion of SOS. Morphological studies have shown that SOS maintains a cartilaginous separation of both bones for up to about 18 years $(5,8)$. Radiological and morphological examinations, however, showed that bony bridges between the two bones appear earlier (7-11). It is assumed that bony bridging results in loss or limited elasticity of the growth plate so that the bone growth on this joint ceases with the first bridging (15). Some degree of SOS closure or even fusion was revealed in the vast majority of syndromic craniosynostosis prior to the $14^{\text {th }}$ year of life (17). The mean time when SOS is closed varies among craniofacial syndromes and between studies, but an earlier closure of the SOS than in controls is sufficiently assured $(18,19)$.

Persistent SOS beyond the age of 20 years is a rare finding $(13,14,30)$. Individual reports on incomplete ossifications of SOS describe a pathogenetic significance for acute diseases $(30,31)$ or the accidental detection in trauma diagnosis $(13,14)$. Transversely oriented hypodense zones across the clivus on cross sectional images of individuals in adolescence or in adulthood are more likely a skull base fracture than a persistent synchondrosis (1). The differential diagnosis of residual SOS from clivus fracture $(13,14)$ generally does not pose any diagnostic problems (12).

SOS fusion in Down syndrome. Longitudinal cephalometric examinations suggest that SOS is closed earlier in patients with Down syndrome than in controls (24). However, this conclusion was only made indirectly via measurements of the skull base sections on cephalograms. The coincidental finding of vestiges of SOS in an older patient with Down syndrome indicates that structural disorders of the ossification of this growth zone can be detected at least occasionally in this patient group. There may be not only temporal but also structural differences in the ossification of SOS between patients with Down syndrome and the normal population. However, inclination of skull base was calculated to be normal in Down syndrome (23). NSBa angle in the presented case is in the normal range. Other authors revealed a flattened skull base and increased skull base angle compared to the control group in Down syndrome $(26,32)$. Down syndrome patients often have malformations of the cervical spine $(29,32)$. SOS fusion correlates with maturation of the cervical vertebrae (33). So far it is unknown to what extent the development of the dorsal skull base correlates with the maturation of the cervical vertebrae of the Down syndrome patient $(2,29)$.

The potential differences of SOS fusion between Down syndrome patients and controls can be recorded in cross sectional imaging, in contrast to lateral cephalometry, in which this region usually cannot be assessed due to the overlapping skull compartments. Radiological studies on the development of the skull base of patients with Down syndrome have so far been carried out on lateral projections of the skull $(20,21,23,25-27)$. Examinations of fetuses with trisomy 21 have shown an unusual scalloping of the basiocciput as a regular finding and, in individual cases, deformations of the bone region (34).

Differences in the development of the base of the skull may be involved in the fact that the phenotype of the trisomy 21 patient is very variable and, as is known, some adults with this syndrome no longer have the characteristic clinical features that can often be seen in adolescence (21).

\section{Conclusion}

The detection of vestiges of sphenooccipital synchondrosis in a Down syndrome patient is an individual finding of a normal variant of skull base ossification. It is currently unknown whether vestiges of the sphenooccipital synchondrosis are indicators of delayed or structurally influenced ossification. 
However, the question remains whether the pattern of sphenoccipital synchondrosis ossification can differ from the spectrum of the ossification period and ossification structure in normal populations.

\section{Conflicts of Interest}

The Authors have no conflicts of interest with regard to the work presented.

\section{Authors' Contributions}

REF treated the patient, researched the literature, and wrote the article. FKK checked the scientific literature and wrote the article. UG provided neuroradiological findings and checked the article. All Authors gave final approval for publication.

\section{References}

1 Okamoto K, Ito J, Tokiguchi S and Furusawa T: High-resolution CT findings in the development of the sphenooccipital synchondrosis. AJNR Am J Neuroradiol 17: 117-120, 1996. PMID: 8770261.

2 Coll G, Lemaire JJ, Di Rocco F, Barthélémy I, Garcier JM, De Schlichting E and Sakka L: Human foramen magnum area and posterior cranial fossa volume growth in relation to cranial base synchondrosis closure in the course of child development. Neurosurgery 79: 722-735, 2016. PMID: 27341342. DOI: 10.1227/NEU.0000000000001309

3 Lang $\mathrm{J}$ and Zeitler-Zapf : [Relative postnatal growth of the basal regions of the cranial fossa]. Neurochirurgia (Stuttg) 36: 179183, 1993. [Article in German] PMID: 8309492. DOI: $10.1055 / \mathrm{s}-2008-1053824$

4 Björk A: Cranial base development: A follow-up x-ray study of the individual variation in growth occurring between the ages of 12 and 20 years and its relation to brain case and face development. Am J Orthodont 41: 198-225, 1955. DOI: 10.1016/0002-9416(55)90005-1

5 Irwin GL: Roentgen determination of the time of closure of the spheno-occipital synchondrosis. Radiology 75: 450-453, 1960 PMID: 13717915. DOI: 10.1148/75.3.450

6 Powell TV and Brodie AG: Closure of the spheno-occipital synchondrosis. Anat Rec 147: 15-23, 1963. PMID: 14062361.

7 Melsen B: Time of closure of the spheno-occipital synchondrosis determined on dry skulls. A radiographic craniometric study. Acta Odontol Scand 27: 73-90, 1969. PMID: 5256953

8 Latham RA: The sella point and postnatal growth of the human cranial base. Am J Orthod 61: 156-162, 1972. PMID: 4500503.

9 Ingervall B and Thilander B: The human spheno-occipital synchondrosis. I. The time of closure appraised macroscopically. Acta Odontol Scand 30: 349-356, 1972. PMID: 4510763.

10 Thilander B and Ingervall B: The human spheno-occipital synchondrosis. II. A histological and microradiographic study of its growth. Acta Odontol Scand 31: 323-334, 1973. PMID: 4520245.

11 Alhazmi A, Vargas E, Palomo JM, Hans M, Latimer B and Simpson S: Timing and rate of spheno-occipital synchondrosis closure and its relationship to puberty. PLoS One 12: e0183305, 2017. PMID: 28827837. DOI: 10.1371/journal.pone.0183305
12 McKinney A: Atlas of normal imaging variations of the brain, skull, and craniocervical vasculature. Springer International Publishing, Cham, Switzerland, 2017, pp. 790-793. DOI: 10.1007/978-3-319-39790-0

13 Kapila A and Chakeres DW: Clivus fracture: CT demonstration. J Comput Assist Tomogr 9: 1142-1144, 1985. PMID: 4056156. DOI: 10.1097/00004728-198511000-00033

14 Adem C, Lafitte F, Jarquin S, Guillem P and Chiras J: [The persistence of a spheno-occipital synchondrosis in an adult]. $\mathrm{J}$ Radiol 80: 863-865, 1999. [Article in French] PMID: 10470617.

15 Goldstein JA, Paliga JT, Wink JD, Bartlett SP, Nah HD and Taylor JA: Earlier evidence of spheno-occipital synchondrosis fusion correlates with severity of midface hypoplasia in patients with syndromic craniosynostosis. Plast Reconstr Surg 134: 504-510, 2014. PMID: 25158708. DOI: 10.1097/PRS.0000000000000419

16 Jensen BL and Kreiborg S: Development of the skull in infants with cleidocranial dysplasia. J Craniofac Genet Dev Biol 13: 8997, 1993. PMID: 8325972.

17 McGrath J, Gerety PA, Derderian CA, Steinbacher DM, Vossough A, Bartlett SP, Nah HD and Taylor JA: Differential closure of the spheno-occipital synchondrosis in syndromic craniosynostosis. Plast Reconstr Surg 130: 681e-689e, 2012. PMID: 22777037. DOI: 10.1097/PRS.0b013e318267d4c0

18 Driessen C, Rijken BF, Doerga PN, Dremmen MH, Joosten KF and Mathijssen IM: The effect of early fusion of the sphenooccipital synchondrosis on midface hypoplasia and obstructive sleep apnea in patients with Crouzon syndrome. J Craniomaxillofac Surg 45: 1069-1073, 2017. PMID: 28479031. DOI: $10.1016 /$ j.jcms.2017.03.024

19 Paliga JT, Goldstein JA, Vossough A, Bartlett SP and Taylor JA: Premature closure of the spheno-occipital synchondrosis in Pfeiffer syndrome: a link to midface hypoplasia. J Craniofac Surg 25: 202-205, 2014. PMID: 24406578. DOI: 10.1097/ SCS.0000000000000386

20 Korayem M and AlKofide E: Size and shape of the sella turcica in subjects with Down syndrome. Orthod Craniofac Res 18: 4350, 2015. PMID: 25323403. DOI: 10.1111/ocr.12059

21 Frostad WA, Cleall JF and Melosky LC: Craniofacial complex in the trisomy 21 syndrome (Down's syndrome). Arch Oral Biol 16: 707-722, 1971. PMID: 4254102. DOI: 10.1016/00039969(71)90116-6

22 Ieshima A, Kisa T, Yoshino K, Takashima S and Takeshita K: A morphometric CT study of Down's syndrome showing small posterior fossa and calcification of basal ganglia. Neuroradiology 26: 493-498, 1984. PMID: 6239108. DOI: 10.1007/bf00342687

23 Quintanilla JS, Biedma BM, Rodríguez MQ, Mora MT, Cunqueiro MM and Pazos MA: Cephalometrics in children with Down's syndrome. Pediatr Radiol 32: 635-643, 2002. PMID: 12195302. DOI: 10.1007/s00247-002-0703-x

24 Alio JJ, Lorenzo J and Iglesias C: Cranial base growth in patients with Down syndrome: a longitudinal study. Am J Orthod Dentofacial Orthop 133: 729-737, 2008. PMID: 18456147. DOI: 10.1016/j.ajodo.2006.03.036

25 Suri S, Tompson BD and Cornfoot L: Cranial base, maxillary and mandibular morphology in Down syndrome. Angle Orthod 80 : 861-869, 2010. PMID: 20578856. DOI: 10.2319/111709-650.1

26 Silva Jesuino FA and Valladares-Neto J: Craniofacial morphological differences between Down syndrome and maxillary deficiency children. Eur J Orthod 35: 124-130, 2013. PMID: 21911842. DOI: 10.1093/ejo/cjr105 
27 Allareddy V, Ching N, Macklin EA, Voelz L, Weintraub G, Davidson E, Prock LA, Rosen D, Brunn R and Skotko BG: Craniofacial features as assessed by lateral cephalometric measurements in children with Down syndrome. Prog Orthod 17: 35, 2016. PMID: 27722998. DOI: 10.1186/s40510-0160148-7

28 Bassed RB, Briggs C and Drummer OH: Analysis of time of closure of the spheno-occipital synchondrosis using computed tomography. Forensic Sci Int 200: 161-164. 2010. PMID: 2045133. DOI: $10.1016 /$ j.forsciint 2010.04 .009

29 Madeline LA and Elster AD: Suture closure in the human chondrocranium: CT assessment. Radiology 196: 747-756, 1995. PMID: 7644639. DOI: 10.1148/radiology.196.3.7644639

30 Wackenheim A: Hypoplasia of the basi-occipital bone and persistence of the spheno-occipital synchondrosis in a patient with transitory supplementary fissure of the basi-occipital. Neuroradiology 27: 226-231, 1985. PMID: 4010922. DOI: $10.1007 / \mathrm{bf00344493}$

31 Wagenaar AE, Mirsky DM, Stence NV, Wine TM and Chan KH: Infection of the spheno-occipital synchondrosis: A morbid complication following adenoidectomy. Int $\mathrm{J}$ Pediatr Otorhinolaryngol 111: 59-62, 2018. PMID: 29958615. DOI: 10.1016/j.ijporl.2018.05.012
32 Rodrigues M, Nunes J, Figueiredo S, Martins de Campos A and Geraldo AF: Neuroimaging assessment in Down syndrome: a pictorial review. Insights Imaging 10: 52, 2019. PMID: 31111268. DOI: 10.1186/s13244-019-0729-3

33 Fernández-Pérez MJ, Alarcón JA, McNamara JA Jr, VelascoTorres M, Benavides E, Galindo-Moreno P and Catena A: Spheno-occipital synchondrosis fusion correlates with cervical vertebrae maturation. PLoS One 11: e0161104, 2016. PMID: 27513752. DOI: 10.1371/journal.pone.0161104

34 Keeling JW, Hansen BF and Kjaer I: Pattern of malformations in the axial skeleton in human trisomy 21 fetuses. Am J Med Genet 68: 466-471, 1997. PMID: 9021023.
Received January 12, 2020

Revised January 26, 2020

Accepted January 28, 2020 